\title{
Dacarbazine/Dactinomycin Regimen
}

National Cancer Institute

\section{Source}

National Cancer Institute. Dacarbazine/Dactinomycin Regimen. NCI Thesaurus. Code C161962.

A chemotherapy regimen consisting of dactinomycin and dacarbazine that may be used in the treatment of advanced melanoma. 